\title{
Gastric Neuroendocrine Tumor pT2 TNM Finding v8
}

National Cancer Institute

\section{Source}

National Cancer Institute. Gastric Neuroendocrine Tumor PT2 TNM Finding v8. NCI

Thesaurus. Code C135038.

Gastric neuroendocrine tumor invading the muscularis propria or is greater than $1 \mathrm{~cm}$ in size. (from AJCC 8th Ed.) 